These suggestions are all contradicted by the experiments reported in this issue $^{1.2}$, which show quite clearly that the recognition properties of Ts cells are determined not by the MHC molecules which they bear, but by selection of their receptor repertoire in the thymus. Thus, lymphocytes from allogenic chimaeras can make the soluble factor with suppressor activity (TsF) of host type even though they do not bear host MHC molecules (they can also make donor-type TsF, presumably because both donor and host $\mathrm{MHC}$ molecules are present during repertoire selection in the thymus). The conclusion is that what was previously regarded as an MHC molecule should now be reinterpreted as an anti-idiotype which binds to that part of the Th cell receptor that recognizes $\mathrm{MHC}$ molecules.

Much of the data of Klein et al. do not contradict this view (see ref. 3 for review). All that is needed is the substitution of an anti-idiotype of the required type wherever an MHC molecule was identified previously as a restriction element.

Note that the concern expressed by Uracz et al. ${ }^{2}$ about expression of I-J on macrophages must be misplaced: host macrophages are presumably needed to elicit idiotypes characteristic of the host MHC-binding site on Th cells that in turn permit TsF to express anti-host idiotype binding activity.

Other possibilities exist but they all seem to involve discarding even more experimental data. Meanwhile we are still waiting for crucial molecular information, particularly about the difference between the mouse strains used to raise anti-I-J antibodies, and about the relative molecular mass 33,000 peptide that is precipitated by these antibodies 5 . If the interpretation offered in the two new reports ${ }^{1.2}$ is correct, the peptide must be part of the Ts cell receptor for antigen $+\mathrm{MHC}$.

There is nothing new for cellular immunology in having to reinterpret quite large chunks of data; that has already happened, for instance, during the elucidation of $I R$ genes. No doubt it will do Ts cells no good at a time when they are, for other reasons, running into heavy weather ${ }^{6}$. Nevertheless, these important papers from Japan must be regarded as a major achievement for the idiotypic network theory, and they will strengthen the view already current ${ }^{6}$ that $T$ cells are even more strongly subject to network control than are B cells.

1. Sumida, T. et al. Nature 316, 738 (1985).

2. Uracz, W., Asano, Y., Abe, Y. \& Tada, T. Nature 316, $741,(1985)$.

3. Klein, J. et al. Immun. Rev. 83, 61 (1985)

4. Bodmer, W. in Progress in Immunology V (eds Yamamura, Y. \& Tada, T.) 959 (Academic, Japan, 1984).

5. Taniguchi, M. et al. Nature 283, 227 (1980)

6. Hedrick, S.M. et al. Proc. natn. Acad. Sci. U.S.A. 82, 531 (1985).

7. Martinez, A. et al. Proc. natn. Acad. Sci. U.S.A. 81, 4520 (1984)

N.A. Mitchison is Professor of Zoology at University College, Gower St, London WCIE $6 B T, U K$.

\section{A Cambrian enigma}

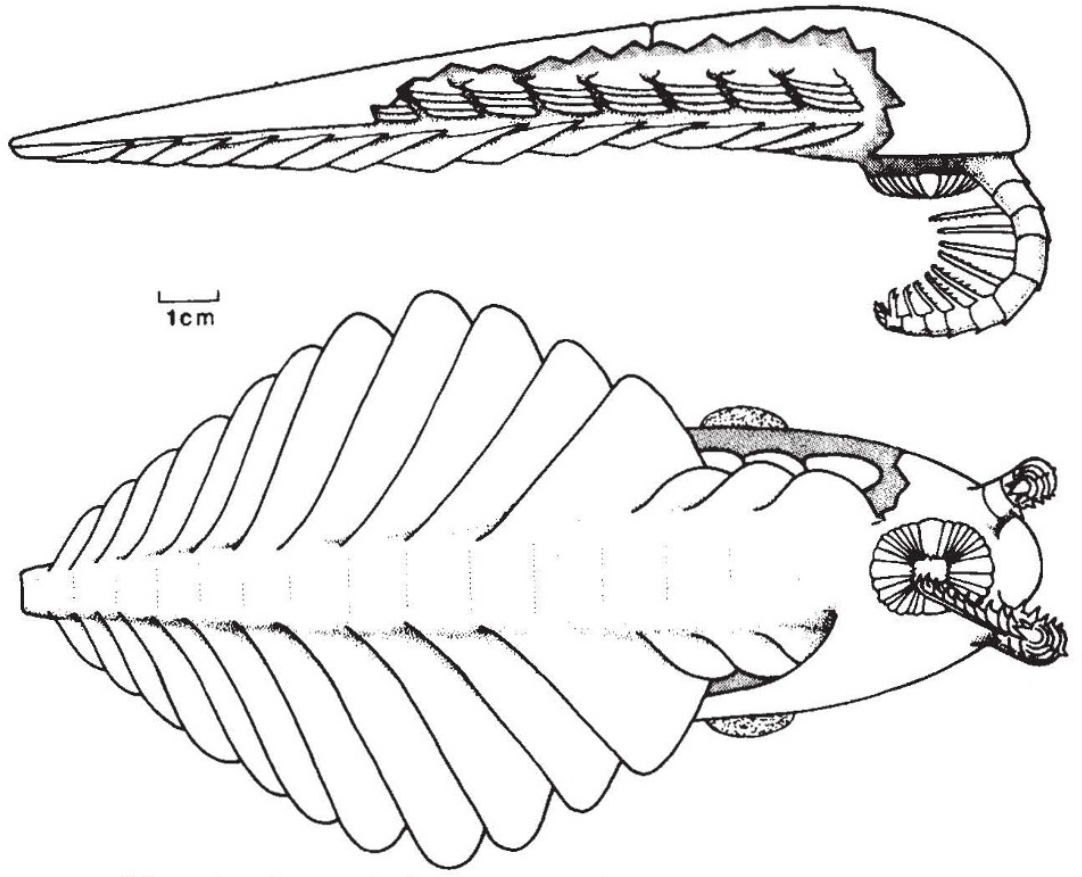

Reconstructed lateral and ventral views of Anomalocaris nathorsti, appendage partly flexed, lateral lobes in still position. In the lateral view, a portion of external cuticle is cut away to show the arrangements of gills. For the ventral view, part of head region cuticle is cut away to show flaps and gills, and blades are omitted from the right appendage to expose the circlet of mouth plates. (From Phil. Trans. R. Soc. B309, 569; 1985).

How well do we know the fossil record? years ago G.E. Hutchinson (Am. Ass. Adv. Recently H.B. Wittington and D.E.G. Briggs (Phil. Trans. R. Soc. B309, 569; 1985) have described in detail yet another surprise from that almost inexhaustible palaeontological treasure-house, the Middle Cambrian Burgess Shale of British Columbia (see Nature News \& Views 302, 570; 1983 and 314,403 ; 1985). Anomalocaris, the bizarre metazoan shown above has had a chequered scientific history; its isolated jointed appendages have been known for many years from both the Lower and Middle Cambrian of North America. They were generally regarded as the detached limbs of a large arthropod. With the discovery of complete specimens, however, a far more bizarre and enigmatic creature has emerged, with two varieties presently recognized (species or sexual dimorphs?). With a length of probably up to half a metre, it is the largest known Cambrian animal. The body was flanked by flexible lobes that served in propulsion, while gills were housed beneath lateral extensions. A single pair of appendages arose from the underside of the head to flank a remarkable jaw that consisted of a series of plates ending in sharp prongs that encircled the mouth. Although the gut contents are not identifiable, the evidence points to Anomalocaris being a predator.

Whittington and Briggs' account is important for our understanding of early metazoan life. Until recently, most palaeontologists believed Cambrian predators rare, exerting a negligible influence in marine communities, although some Sci. Publ. 67,$85 ; 1961)$ suggested that this was an artefact of the fossil record that favours suspension and deposit feeders with robust skeletons (Schopf, T.J.M. Paleobiology 4, 261; 1978). Anomalocaris is the latest, if most ferocious, addition to the lightly skeletized and soft-bodied pre dators that have been found in the Burgess Shale (Conway Morris, S. Phil. Trans. $R$. Soc. B 307,$507 ;$ 1985). At some horizons that have yielded Anomalocaris there are also trilobites showing evidence of unsuccessful attack, and Whittington and Briggs speculate on how the action of the jaw apparatus can be reconciled with the damage. But some injured trilobites are not associated with Anomalocaris and perhaps represent the unwelcome attention of other large predators that so far have eluded discovery (Conway Morris, S. \& Jenkins, R.J.F. Alcheringa 9; in the press).

The Burgess Shale contains an extra ordinary variety of metazoans which, if found alive today, would probably be hailed as new phyla. Anomalocaris is no exception; despite the arthropod-like anterior appendages, the rest of the anatomy is irreconcilable with the arthropod bodyplan and the jaw apparatus appears to have no parallel in the Metazoa. It is a reminder of how little we know about the early diversification and ecology of the metazoans. Simon Conway Morris

Simon Conway Morris is in the Department of Earth Sciences, University of Cambridge, Cambridge CB23EQ,UK. 